\title{
Understanding the Detection Mechanisms and Ability of Molecular Hydrogen on Three-Dimensional Bicontinuous Nanoporous Reduced Graphene Oxide
}

\author{
Yoshikazu Ito ${ }^{1, *(\mathbb{D}}$, Megumi Kayanuma ${ }^{2,3}$, Yasuteru Shigeta ${ }^{3}$, Jun-ichi Fujita ${ }^{1}$ and \\ Yoichi Tanabe ${ }^{4}(\mathbb{D}$ \\ 1 Institute of Applied Physics, Graduate School of Pure and Applied Sciences, University of Tsukuba, \\ 1-1-1 Tennodai, Tsukuba 305-8571, Japan; fujita@bk.tsukuba.ac.jp \\ 2 Research Center for Computational Design of Advanced Functional Materials, \\ National Institute of Advanced Industrial Science and Technology, 1-1-1 Umezono, Tsukuba, Ibaraki \\ 305-8568, Japan; megumi.kayanuma@gmail.com \\ 3 Center for Computational Sciences, University of Tsukuba, 1-1-1 Tennodai, Tsukuba 305-8577, Japan; \\ shigeta@ccs.tsukuba.ac.jp \\ 4 Department of Applied Science, Okayama University of Science, Okayama 700-0005, Japan; \\ tanabe@das.ous.ac.jp \\ * Correspondence: ito.yoshikazu.ga@u.tsukuba.ac.jp
}

Received: 1 April 2020; Accepted: 12 May 2020; Published: 14 May 2020

\begin{abstract}
Environmental safety has become increasingly important with respect to hydrogen use in society. Monitoring techniques for explosive gaseous hydrogen are essential to ensure safety in sustainable hydrogen utilization. Here, we reveal molecular hydrogen detection mechanisms with monolithic three-dimensional nanoporous reduced graphene oxide under gaseous hydrogen flow and at room temperature. Nanoporous reduced graphene oxide significantly increased molecular hydrogen physisorption without the need to employ catalytic metals or heating. This can be explained by the significantly increased surface area in comparison to two-dimensional graphene sheets and conventional reduced graphene oxide flakes. Using this large surface area, molecular hydrogen adsorption behaviors were accurately observed. In particular, we found that the electrical resistance firstly decreased and then gradually increased with higher gaseous hydrogen concentrations. The resistance decrease was due to charge transfer from the molecular hydrogen to the reduced graphene oxide at adsorbed molecular hydrogen concentrations lower than $2.8 \mathrm{ppm}$; conversely, the resistance increase was a result of Coulomb scattering effects at adsorbed molecular hydrogen concentrations exceeding $5.0 \mathrm{ppm}$, as supported by density functional theory. These findings not only provide the detailed adsorption mechanisms of molecular hydrogen, but also advance the development of catalyst-free non-heated physisorption-type molecular detection devices.
\end{abstract}

Keywords: porous graphene; graphene oxide; hydrogen adsorption

\section{Introduction}

Detection of molecular hydrogen in ambient atmospheres has become increasingly important because renewable energy, especially hydrogen-based energy, is a focus for the development of sustainable societies [1,2]. Users may encounter some risks associated with the initial leakage of molecular hydrogen from equipment, and explosions can occur with the deployment of molecular hydrogen equipment such as fuel cells. Therefore, the identification of an accurate detection mechanism for molecular hydrogen under hydrogen flow conditions is urgent for the further development of hydrogen gas sensors and the environmental safety of societies that utilize hydrogen. 
Conventional molecules are detected by catalytic combustion, resistance change, and thermal conductivity change [3-7]. Detection is generally accompanied by chemical reactions on the detection element. Heating of the elements may be required for molecular detection. However, such systems might lead to undesirable situations such as spark generation, irreversible exothermic reactions, or overheating, which could occur under abnormal operating conditions in uncontrolled devices. Thus, the possible hazards related to hydrogen gas combustion in conventional gas detection devices cannot be completely excluded. Recently, non-heated and non-chemical reaction detection mechanisms have been reported, employing monolayer or multilayer graphene. These graphene sensors successfully detected gaseous polar molecules such as $\mathrm{H}_{2} \mathrm{O}, \mathrm{CO}, \mathrm{CO}_{2}, \mathrm{NO}, \mathrm{NO}_{2}, \mathrm{O}_{2}, \mathrm{SO}_{2}$, and $\mathrm{NH}_{3}$ at parts per billion (ppb) and parts per million (ppm) levels [8-13]. Moreover, reduced graphene oxide (rGO) flakes demonstrated highly sensitive polar molecule detection without any catalytic metals [14-19], because the molecular adsorption sites of hydroxyl $(\mathrm{C}-\mathrm{OH})$, epoxide $(\mathrm{C}-\mathrm{O}-\mathrm{C})$, ketone $(\mathrm{C}=\mathrm{O})$, and carboxyl $(\mathrm{COOH})$ groups on $\mathrm{rGO}$ are effective physisorption sites. However, the detection mechanism of non-polar molecules such as molecular hydrogen $\left(\mathrm{H}_{2}\right)$ using either graphene or rGO flakes is not precisely discussed in the literature because the weak physisorption strength and insufficient molecular detection area of the graphene surface mask the details of the electrical resistance behaviors. Since catalytic $\mathrm{H}_{2}$ detection with $\mathrm{Pt}[20,21], \mathrm{Pd}[22-25], \mathrm{Au}[26], \mathrm{ZnO}[27,28]$, and $\mathrm{SnO}_{2}[29,30]$ at high temperatures has been predominantly employed for detecting $\mathrm{H}_{2}$, the significant challenge of realizing physisorption of non-polar $\mathrm{H}_{2}$ and revealing the detection mechanisms in detail remains in the development of non-catalytic $\mathrm{H}_{2}$ detection devices.

Here, we synthesized a single and monolithic nanoporous reduced graphene oxide (np-rGO) sheet. The synthesized sheet had an edge-free bicontinuous and open porous three-dimensional (3D) structure and was treated by a modified Hummer method. The np-rGO sheet maintained a projected surface area 500 times larger than that of a standard two-dimensional (2D) graphene sheet, performing significantly accurate detection via molecular physisorption of $\mathrm{H}_{2}$ as compared to pristine nanoporous unoxidized graphene and rGO flakes. Such physisorption detection mechanisms based on a large surface area provide a new class of design direction for non-heated, flow-type, and physisorption-type graphene-based detection systems for non-polar gas molecules without metal catalysts.

\section{Materials and Methods}

\subsection{Preparation of Nanoporous Ni Substrates}

$\mathrm{Ni}_{30} \mathrm{Mn}_{70}$ ingots were prepared by melting pure $\mathrm{Ni}$ and $\mathrm{Mn}$ (purity $>99.9$ at.\%) in an Ar-protected arc melting furnace. After annealing at $900{ }^{\circ} \mathrm{C}$ for $24 \mathrm{~h}$ for microstructure and composition homogenization, the ingots were cold-rolled into thin sheets $(50 \mu \mathrm{m})$ at room temperature. Nanoporous Ni was prepared by chemical dealloying in a $1.0 \mathrm{M}\left(\mathrm{NH}_{4}\right)_{2} \mathrm{SO}_{4}$ aqueous solution at $50{ }^{\circ} \mathrm{C}$ overnight. After dealloying, the samples were rinsed thoroughly with distilled water and then rinsed with ethanol before vacuum drying.

\subsection{Preparation of Nanoporous Graphene}

The nanoporous Ni substrates were loaded in a quartz tube $(\varnothing 26 \times \varnothing 22 \times 250 \mathrm{~mm})$, placed in a quartz tube furnace $(\varnothing 30 \times \varnothing 27 \times 1000 \mathrm{~mm})$, and annealed at $800^{\circ} \mathrm{C}$ under a mixed gas flow $(200 \mathrm{sccm}$ Ar and $100 \mathrm{sccm} \mathrm{H}_{2}$ ) for $3 \mathrm{~min}$ [31-35]. After the reduction pre-treatment, a mixed atmosphere of $\mathrm{H}_{2}$ (100 sccm), Ar (200 sccm), and benzene (0.5 mbar, 99.8\%, anhydrous, Aldrich) was introduced for graphene growth at $800{ }^{\circ} \mathrm{C}$ for $2 \mathrm{~min}$. Subsequently, the furnace was opened for the rapid cooling of the inner quartz tube. The nanoporous $\mathrm{Ni}$ substrate was etched in a $1.0 \mathrm{M} \mathrm{HCl}$ solution and then the remaining nanoporous graphene was transferred into a $2.0 \mathrm{M} \mathrm{HCl}$ solution to completely remove residual Ni. The samples were repeatedly washed with water and subsequently kept in water. 


\subsection{Preparation of Nanoporous Graphene Oxide and Nanoporous Reduced Graphene Oxide}

The nanoporous graphene dispersed in water was oxidized via a modified Hummer method [36]. A single graphene sheet was added to a $\mathrm{KMnO}_{4}(0.45 \mathrm{~g})$, concentrated $\mathrm{H}_{2} \mathrm{SO}_{4}(3.45 \mathrm{~mL})$, and $\mathrm{NaNO}_{2}$ $(0.075 \mathrm{~g})$ mixture without stirring. After $10 \mathrm{~min}$, the mixture was diluted in an aqueous $\mathrm{H}_{2} \mathrm{SO}_{4}(5 \%)$ solution. Then, an aqueous $\mathrm{H}_{2} \mathrm{O}_{2}(30 \%)$ solution diluted in aqueous $\mathrm{H}_{2} \mathrm{SO}_{4}(5 \%)$ was slowly added to the mixture. The obtained transparent sheet was then washed several times with a mixture of aqueous $\mathrm{H}_{2} \mathrm{SO}_{4}(3 \%)$ and $\mathrm{H}_{2} \mathrm{O}_{2}(0.5 \%)$. The nanoporous graphene oxide (GO) sheet was then repeatedly washed with water and kept in 2-propanol. The samples were dried by a conventional supercritical $\mathrm{CO}_{2}$ drying method. The dried GO sample was transferred onto a $\mathrm{SiO}_{2}$ substrate and then connected to fine $\mathrm{Cu}$ lines (twisted) using silver paste in a standard pseudo four-probe configuration. The reduced graphene oxide (rGO) sample was prepared by annealing the GO sample on the substrate at $150{ }^{\circ} \mathrm{C}$ using ribbon heaters under vacuum in a self-made atmosphere-controlled glass cell connected to Swagelok vacuum components.

\subsection{Supercritical Drying Procedure}

To prevent the collapse of the fragile nanoporous structures caused by water capillary forces during drying, the nanoporous graphene and rGO samples immersed in 2-propanol were dried by using supercritical $\mathrm{CO}_{2}\left(\mathrm{scCO}_{2}\right)$ and thus 2-propanol was substituted for $\mathrm{CO}_{2}$ without the action of capillary forces. To this end, the nanoporous graphene sample was firstly transferred to a vial (volume: $5 \mathrm{~mL}$ ) filled with 2-propanol $(400 \mu \mathrm{L})$, and then the bottle was placed in an 80-mL pressure-resistant container (TAIATSU techno Corp). After removing the air inside the container via $\mathrm{CO}_{2}$ purging, the pressure of the container was gradually increased to $15 \mathrm{MPa}$ by introducing liquid $\mathrm{CO}_{2}\left(5 \mathrm{Mpa},-4{ }^{\circ} \mathrm{C}\right.$, density: $\left.0.964 \mathrm{~g} \mathrm{~mL}^{-1}\right)$ at a flow rate of $20 \mathrm{~mL} \mathrm{~min}^{-1}\left(\sim 19 \mathrm{~g} \mathrm{~min}^{-1}\right)$ using a high-pressure plunger pump (NP-KX-540, NIHON SEIMITSU KAGAKU Co. Ltd.). The $\mathrm{scCO}_{2}$ drying process was performed at $70{ }^{\circ} \mathrm{C}$ and at a constant $\mathrm{CO}_{2}$ flow rate of $5 \mathrm{~mL} \mathrm{~min}{ }^{-1}\left(\sim 4.8 \mathrm{~g} \mathrm{~min}^{-1}\right)$ by forming a homogeneous phase of 2-propanol and $\mathrm{scCO}_{2}$, thus minimizing the capillary force. The pressure was maintained at $15 \mathrm{MPa}$ for $5 \mathrm{~h}$ during the drying process. After drying the sample completely, the temperature was set at $40{ }^{\circ} \mathrm{C}$ and the container was gradually depressurized over $43 \mathrm{~h}$ from $15 \mathrm{MPa}$ to atmospheric pressure by gradually pumping $\mathrm{CO}_{2}$ from the system.

\section{Microstructure Characterization and Property Measurements}

\subsection{Imaging and Spectroscopic Characterization}

The microstructures of the nanoporous GO and nanoporous rGO were characterized using a scanning electron microscope (SEM; JEOL JSM-6700). Chemical analyses on the graphene samples were performed via X-ray photoelectron spectroscopy (XPS; AXIS ultra DLD, Shimazu) with an Al Ka X-ray monochromator. Raman spectra were obtained using a micro-Raman spectrometer (Renishaw InVia Reflex 532) with an incident wavelength of $532.5 \mathrm{~nm}$. The laser power was set at $0.1 \mathrm{~mW}$ to avoid possible damage or unexpected reduction by laser irradiation. The graphene samples were placed on a background-free glass slide. The accumulation time of each spectrum was $100 \mathrm{~s}$.

\subsection{Transport Property Measurements}

The temperature and magnetic field dependences of the electrical resistance of reduced nanoporous graphene oxide were measured using the four-probe method under a magnetic field at $300 \mathrm{~K}$. The reduced

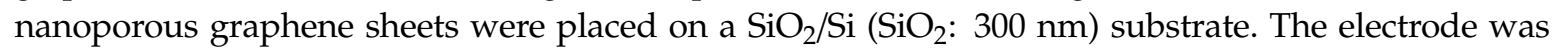
fabricated using Ag epoxy (H20E, Epoxy Technology). The electrical resistance measurements were performed using the Physical Properties Measurement System (PPMS; Quantum Design). 


\subsection{Gas Detection Device Fabrication and Measurements}

A molecular detection glass cell was fabricated using an atmosphere-controlled separable three-neck glass cell with an O-ring. Swagelok vacuum components were inserted into two rubber stoppers, and the stoppers were installed in two of the necks. The Swagelok vacuum components were connected to mass flow controllers and a rotary pump. Four $\mathrm{Cu}$ wires $(1.5 \mathrm{~mm})$ and a thermocouple (type K) were inserted in a rubber stopper, and the stopper was installed in the third neck of the cell to communicate the inside and outside of the cell and the device; all connections were completely sealed with Torr Seal ${ }^{\circledR}$ to avoid leakage. The detection element of the nanoporous GO sheet $(7.2 \mathrm{~mm} \times 2.5 \mathrm{~mm})$ was attached on $\mathrm{SiO}_{2}$ substrate through fine twisted $\mathrm{Cu}$ lines fixed with silver paste. Then, the substrate was transferred to the glass cell and the fine $\mathrm{Cu}$ lines were electrically connected to the $\mathrm{Cu}$ wires $(1.5 \mathrm{~mm})$ inside the cell. The temperature inside the cell was controlled by an external ribbon heater for thermal reduction of nanoporous GO in the cell. The whole system and the connected vacuum components were heated to $150^{\circ} \mathrm{C}$, and the $\mathrm{GO}$ (already connected to the $\mathrm{Cu}$ wires $(1.5 \mathrm{~mm})$ through the fine $\mathrm{Cu}$ wires) was thermally reduced to $\mathrm{rGO}$ under vacuum (5 Pa). Briefly, the temperature for thermal reduction was fixed at $150{ }^{\circ} \mathrm{C}$ and the heating time was set at $4 \mathrm{~h}$ for oxygen contents of 20.0 at. $\%, 6 \mathrm{~h}$ for oxygen contents of 18.2 at. $\%$, and $12 \mathrm{~h}$ for oxygen contents of 10.8 at. $\%$. After cooling down to the room temperature $\left(23^{\circ} \mathrm{C}\right)$, the thermally reduced GO samples were sequentially measured in the cell by a standard pseudo four-probe method using a semiconductor parameter analyzer (Keysight B1500A). The applied voltage was set at $-9 \mathrm{~V}$ for the nanoporous rGO samples (with chemical oxidation and thermal reduction treatments) and to $-10 \mathrm{mV}$ for the pristine nanoporous graphene (without oxidation and reduction treatments) under a mixture of gaseous argon (Ar: $>99.9999$ vol. \%, $\mathrm{H}_{2} \mathrm{O}:<-80^{\circ} \mathrm{C}, \mathrm{O}_{2}:<0.1 \mathrm{ppm}, \mathrm{CH}_{4}:<0.1 \mathrm{ppm}, \mathrm{CO}_{2}:<0.1 \mathrm{ppm}, \mathrm{CO}:<0.1 \mathrm{ppm}, \mathrm{N}_{2}:<0.6 \mathrm{ppm}$, $\left.\mathrm{H}_{2}:<0.1 \mathrm{ppm}\right)$. The ultrapure gaseous Ar continuously flowed until the resistance value stabilized to exclude unexpected influences of impurities such as $\mathrm{H}_{2} \mathrm{O}, \mathrm{O}_{2}, \mathrm{CH}_{4}, \mathrm{CO}_{2}, \mathrm{CO}$, and $\mathrm{H}_{2}$. Thus, any changes in resistance values under the mixture of $\mathrm{H}_{2} / \mathrm{Ar}$ gas flowing could be attributed to the introduction of ultrapure $\mathrm{H}_{2}$ gas. After the resistance was stable, the mixture of gaseous $\mathrm{Ar}$ and gaseous hydrogen $\left(\mathrm{H}_{2}:>99.9999\right.$ vol. $\%, \mathrm{H}_{2} \mathrm{O}:<-80{ }^{\circ} \mathrm{C}, \mathrm{O}_{2}:<0.1 \mathrm{ppm}, \mathrm{CH}_{4}:<0.1 \mathrm{ppm}, \mathrm{CO}_{2}:<0.1 \mathrm{ppm}, \mathrm{CO}$ : $<0.1 \mathrm{ppm}$ ) was introduced in the cell. The total flow rate of the mixed gas was set at $30 \mathrm{sccm}$. To obtain the $1 \mathrm{ppm} \mathrm{H}_{2}$ gas in the Ar flow case, gaseous hydrogen was mixed with gaseous argon to a $\mathrm{H}_{2}$ concentration of $0.0001 \mathrm{vol} . \%$, and then the mixed gas was supplied by the mass flow controllers at a flow rate of $30 \mathrm{sccm}$ (the partial pressure of hydrogen was $0.10 \mathrm{~Pa}$ ). Note that flow rates exceeding $30 \mathrm{sccm}$ deformed the atomically thin porous structures, and the resistance values became unstable. Before all measurements, the whole system was vacuumed for $12 \mathrm{~h}$ at room temperature to avoid further thermal reduction of the rGO.

\section{Density Functional Theory Calculations}

The geometries of the surface models $\left(\mathrm{C}_{54} \mathrm{H}_{18}, \mathrm{C}_{54} \mathrm{H}_{18}-2 \mathrm{OH}, \mathrm{C}_{54} \mathrm{H}_{18}-2 \mathrm{O}, \mathrm{C}_{53} \mathrm{H}_{18}-\mathrm{COOH}\right.$, and $\mathrm{C}_{53} \mathrm{H}_{18}-2 \mathrm{O}$ ) were optimized using the density functional theory (DFT) method with the B3LYP functional $[37,38]$ and considering the D3 version on Grimme's dispersion correction [39] with 6-311G $(\mathrm{d}, \mathrm{p})$ basis sets [40]. For the graphene oxide models, the coordinates of the terminal $\mathrm{H}$ atoms were fixed to those of the pristine graphene to model a large surface that would prevent distortion. Several structures from the graphene oxide models were compared and the most stable alternative was chosen for the calculation of $\mathrm{H}_{2}$ adsorption. All calculations were performed using Gaussian 16 quantum chemistry software [41].

\section{Results}

\subsection{Material Characterization}

The transparent 3D np-GO (Figure 1a) was dried by a conventional supercritical $\mathrm{CO}_{2}$ fluid method, attached to a $\mathrm{SiO}_{2}$ substrate with the $\mathrm{Cu}$ wires (Figure $1 \mathrm{~b}$ ), and transferred to the atmosphere-controlled 
glass cell to reduce the np-GO sample at $150^{\circ} \mathrm{C}$ for $4 \mathrm{~h}$ under vacuum. The dried np-rGO maintained the original morphology of the pristine 3D nanoporous graphene without any obvious flakes or holes after the oxidation and reduction processes (Figure 2a and Figure S1). The specific surface area and average pore size were $\sim 1000 \mathrm{~m}^{2} \mathrm{~g}^{-1}$ and $\sim 200 \mathrm{~nm}$, respectively, and the total projected surface area exceeded 500 times that of the 2D graphene sheet [32,36,42]. Moreover, it was determined by high-resolution transmission electron microscopy that amorphous-like graphene lattices on np-rGO were partially crystallized after thermal reduction, and electron energy-loss spectroscopy (EELS) spectra also demonstrated regeneration of $s p^{2}$ bonds by post reduction [36]. EELS mappings confirmed that the oxidation species were almost homogeneously distributed on the nanoporous structures [36].

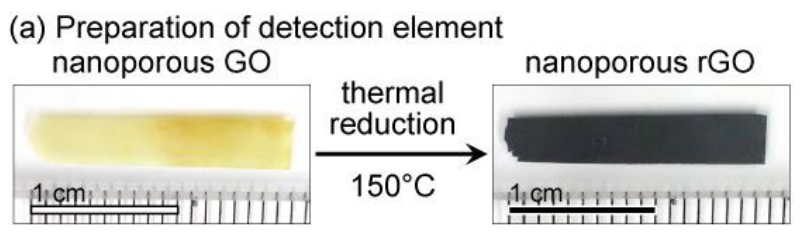

(b) Schematic model

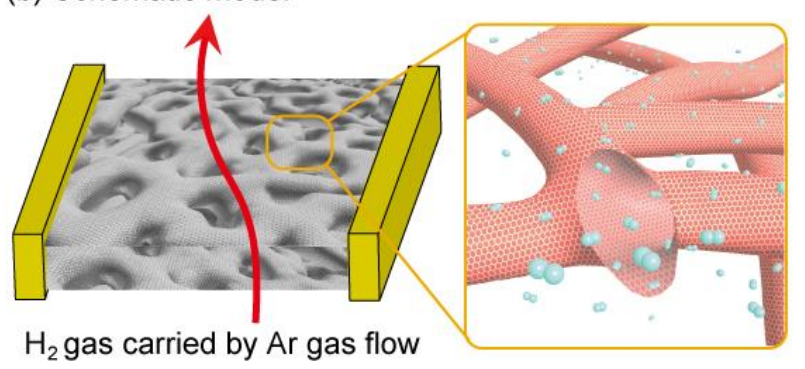

Figure 1. Nanoporous reduced graphene oxide. (a) Optical images of nanoporous graphene oxide (GO) and nanoporous reduced GO (rGO), and (b) a schematic illustration of the detection element of nanoporous rGO with details. The inset shows the tubular graphene ligaments.

Raman spectra were analyzed to estimate the quality of the graphene samples and their respective oxidation levels (Figure $2 \mathrm{~b}$ and Figure $\mathrm{S} 2$ and Table S1). The pristine nanoporous graphene showed an intensity ratio of the $2 \mathrm{D}$ and $\mathrm{G}$ bands $\left(I_{2 \mathrm{D}} / I_{\mathrm{G}}\right)$ of 2.5 and of the $\mathrm{D}$ and $\mathrm{G}$ bands $\left(I_{\mathrm{D}} / I_{\mathrm{G}}\right)$ of 0.08 , corresponding to high-quality 1-2 layer graphene without detectable amorphous carbon features [43,44]. After the oxidation process, the np-GO showed a large defect density $\left(I_{\mathrm{D}} / I_{\mathrm{G}}\right.$ of 1.6 and $I_{2 \mathrm{D}} / I_{\mathrm{G}}$ of 0.91$)$. The np-rGO partially restored graphene features $\left(I_{\mathrm{D}} / I_{\mathrm{G}}\right.$ of 0.98 and an $I_{2 \mathrm{D}} / I_{\mathrm{G}}$ of 1.7$)$. The full width at half maximum (FWHM) values of the $\mathrm{D}, \mathrm{G}$, and $2 \mathrm{D}$ bands of the np-rGO were significantly increased in comparison to the pristine nanoporous graphene. Chemical binding was further investigated by XPS. The C1s X-ray photoelectron spectrum (Figure 2c,d, Figures S3 and S4) demonstrated an oxygen content of 4.7 at.\% for pristine nanoporous graphene, 32.8 at. $\%$ for np-GO, and 20.0 at. $\%$ for np-rGO. Oxidized carbon species such as 10.7 at.\% C-O and/or C-O-C $(286.6 \mathrm{eV}), 8.7$ at. $\% \mathrm{C}=\mathrm{O}(288.8 \mathrm{eV})$, and 0.6 at. $\% \mathrm{C}(\mathrm{O}) \mathrm{OH}(290 \mathrm{eV})$ were observed on the np-rGO, which was consistent with reported observations [36,45-47]. The FWHM of graphitic carbon at $284.5 \mathrm{eV}$ was broadened from $0.71 \mathrm{eV}$ of pristine nanoporous graphene to $2.0 \mathrm{eV}$ of np-GO after oxidation and narrowed to $1.3 \mathrm{eV}$ of np-rGO after reduction; this was associated with the mixed states of orbitals $s p^{2}$ and $s p^{3}[46,47]$. Therefore, the np-rGO presented a significant number of defect structures containing $\mathrm{C}-\mathrm{O}, \mathrm{C}-\mathrm{O}-\mathrm{C}$, and $\mathrm{C}=\mathrm{O}$ with a small number of $\mathrm{C}(\mathrm{O}) \mathrm{OH}$. Moreover, it was confirmed that the $\mathrm{X}$-ray photoelectron spectra of $\mathrm{Ni} 2 \mathrm{p}$ and Mn $2 p$ were not detected in any of the samples (Figures S3 and S4), which was consistent with the absence of $\mathrm{Ni}$ and $\mathrm{Mn}$ compounds in the X-ray diffraction (XRD) spectrum (Figure S5). Other np-rGO samples with different oxygen contents were similarly characterized (Figures S2-S4). Furthermore, the inter-defect distance on the graphene lattice estimated by Raman spectra and the distance between functional groups estimated by XPS were compared. The average inter-defect distance was estimated by the $I_{\mathrm{D}} / I_{\mathrm{G}}$ from the Tuinstra-Koenig relation: $I_{\mathrm{D}} / I_{\mathrm{G}}=C(\lambda) / L_{\mathrm{D}}$, where $C(\lambda)$ is a proportionality constant at 
the excitation laser wavelength $\lambda$ and $L_{\mathrm{D}}$ is the average distance between the defects [48-50]. Under the assumption that this relation could be applied to the rGO system, the $L_{\mathrm{D}}$ value of np-rGO with an oxygen content of 20 at. $\%\left(I_{\mathrm{D}} / I_{\mathrm{G}}=0.98\right)$ was approximately $8-10 \mathrm{~nm}$, which was almost of the same order as the distance between the oxidized functional groups estimated by the atomic concentrations.

The transport properties of nanoporous graphene and np-rGO were measured at $300 \mathrm{~K}$ by a standard four-probe method. The typical electrical conductances and electron mobilities of the nanoporous graphene samples were $500-1000 \mathrm{~S} \mathrm{~cm}^{-1}$ and $5000-8000 \mathrm{~cm}^{2} \mathrm{~V}^{-1} \mathrm{~s}^{-1}$, respectively [35,51]. The typical electrical conductances and electron mobilities of the np-rGO samples with degrees of oxidation of 19.6-23.3 at.\% were $0.0025-0.043 \mathrm{~S} \mathrm{~cm}^{-1}$ and $0.31-1.0 \mathrm{~cm}^{2} \mathrm{~V}^{-1} \mathrm{~s}^{-1}$, respectively [36]. Note that the electron mobility of the np-rGO samples was ca. 2 orders of magnitude higher than that of conventional rGO films formed by small flakes under the same thermal reduction conditions $\left(0.0015-0.06 \mathrm{~cm}^{2} \mathrm{~V}^{-1} \mathrm{~s}^{-1}\right)$ [52]. Therefore, the electrons on np-rGO were moved smoothly owing to the unique bicontinuous structures.
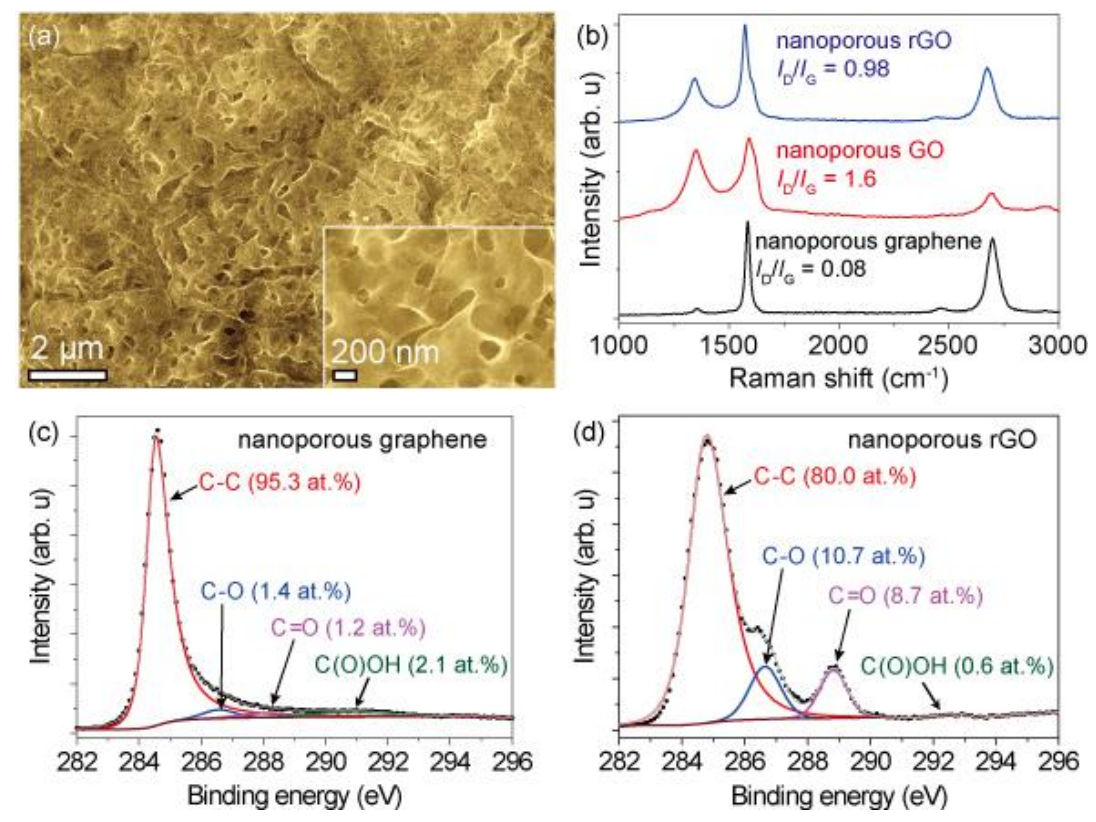

Figure 2. Characterizations of nanoporous rGO. (a) SEM images of nanoporous rGO with an oxygen content of 20.0 at.\%. (b) Raman spectra of pristine nanoporous graphene, nanoporous GO, and nanoporous rGO. X-ray photoelectron spectra of C 1s for (c) pristine nanoporous graphene and (d) nanoporous $\mathrm{rGO}$ with an oxygen content of 20.0 at.\%.

\subsection{Hydrogen Adsorption}

To evaluate the molecular physisorption ability of $\mathrm{H}_{2}$, we measured the time dependence of resistance changes under the $\mathrm{H}_{2} / \mathrm{Ar}$ mixed gas in the atmosphere-controlled glass cell. Firstly, we confirmed the reversibility of molecular physisorption of $\mathrm{H}_{2}$ under $\mathrm{Ar}$ and $\mathrm{H}_{2} / \mathrm{Ar}$ flow conditions ( $500 \mathrm{ppm} \mathrm{H}_{2}$, Figure 3a) on the np-rGO with an oxygen content of 20.0 at.\%. In the first step, pure $\mathrm{Ar}$ gas flowed until the resistance value became constant, and then $\mathrm{H}_{2} / \mathrm{Ar}$ gas flowed; time was necessary to replace the pure Ar gas in the cell with $\mathrm{H}_{2} / \mathrm{Ar}$ gas. The resistance values gradually increased as the $\mathrm{H}_{2}$ reached the surface of the np-rGO. The resistance values kept substantially constant at the equilibrium states of adsorption and desorption of $\mathrm{H}_{2}$ under the $\mathrm{H}_{2} / \mathrm{Ar}$ gas flow. The resistance values gradually decreased to the initial resistance value after stopping the $\mathrm{H}_{2}$ gas supply (i.e., $30 \mathrm{sccm}$ pure Ar gas flow only). The response was relatively slower than that of conventional catalytic metal-based gas detection systems, probably because the replacement of $\mathrm{Ar}$ by $\mathrm{H}_{2}$ requires time owing to the low flow rate and geometrically requires time to reach the surface due to the complicated porous structure [32] in comparison to the flat structures [20-30]. 
The change in resistance at $\mathrm{H}_{2}$ gas volume concentrations from $0.1 \mathrm{ppm}$ to $10,000 \mathrm{ppm}$ under $\mathrm{H}_{2}$ /Ar gas flow (30 sccm in total) was investigated for the np-rGO with an oxygen content of 20.0 at. $\%$ (Figure $3 \mathrm{~b}$ and Figure S6) and nanoporous graphene (Figure 3c). We found that the time-dependent resistance values at $-9.0 \mathrm{~V}$ of the np-rGO (initial resistance: $742 \mathrm{M} \Omega$ ) increased above 5 ppm $\mathrm{H}_{2}$ under $\mathrm{H}_{2}$ /Ar gas flow, whereas they decreased below $2.8 \mathrm{ppm} \mathrm{H}_{2}$. Each change of resistance value was normalized to the equilibrium state before $\mathrm{H}_{2}$ adsorption (only Ar flow state) and plotted for the various $\mathrm{H}_{2}$ ppm values (Figure 3d). The normalized changes (\%) were proportional to logarithmic $\mathrm{H}_{2} \mathrm{ppm}$ values at above 5 ppm $\mathrm{H}_{2}$ under $\mathrm{H}_{2}$ /Ar gas flow. The nanoporous graphene (initial resistance: $33.8 \Omega$ ) showed a similar behavior but did not show large changes in resistance values for $0.1-10,000 \mathrm{ppm}_{2}$ under the same conditions. Thus, the large changes in np-rGO were attributed to the oxidized functional groups on the graphene. Moreover, both samples exhibited a local minimum at approximately $1 \mathrm{ppm}$ $\mathrm{H}_{2}$ under $\mathrm{H}_{2}$ /Ar gas flow. Note that these increases and decreases have not been reported for graphene and rGO detection systems [8,14-19]. Furthermore, the oxidization level dependence of the resistance changes was similarly investigated (Figure S7). The np-rGO samples with oxygen contents of 10.8 at.\% (initial resistance: $11.1 \mathrm{k} \Omega$ ) and 18.2 at.\% (initial resistance: $1.26 \mathrm{M} \Omega$ ) showed similar behaviors, but smaller resistance changes at typical $\mathrm{H}_{2}$ ppm values under $\mathrm{H}_{2}$ /Ar gas flow in comparison to the np-rGO sample with an oxygen content of 20.0 at.\%.
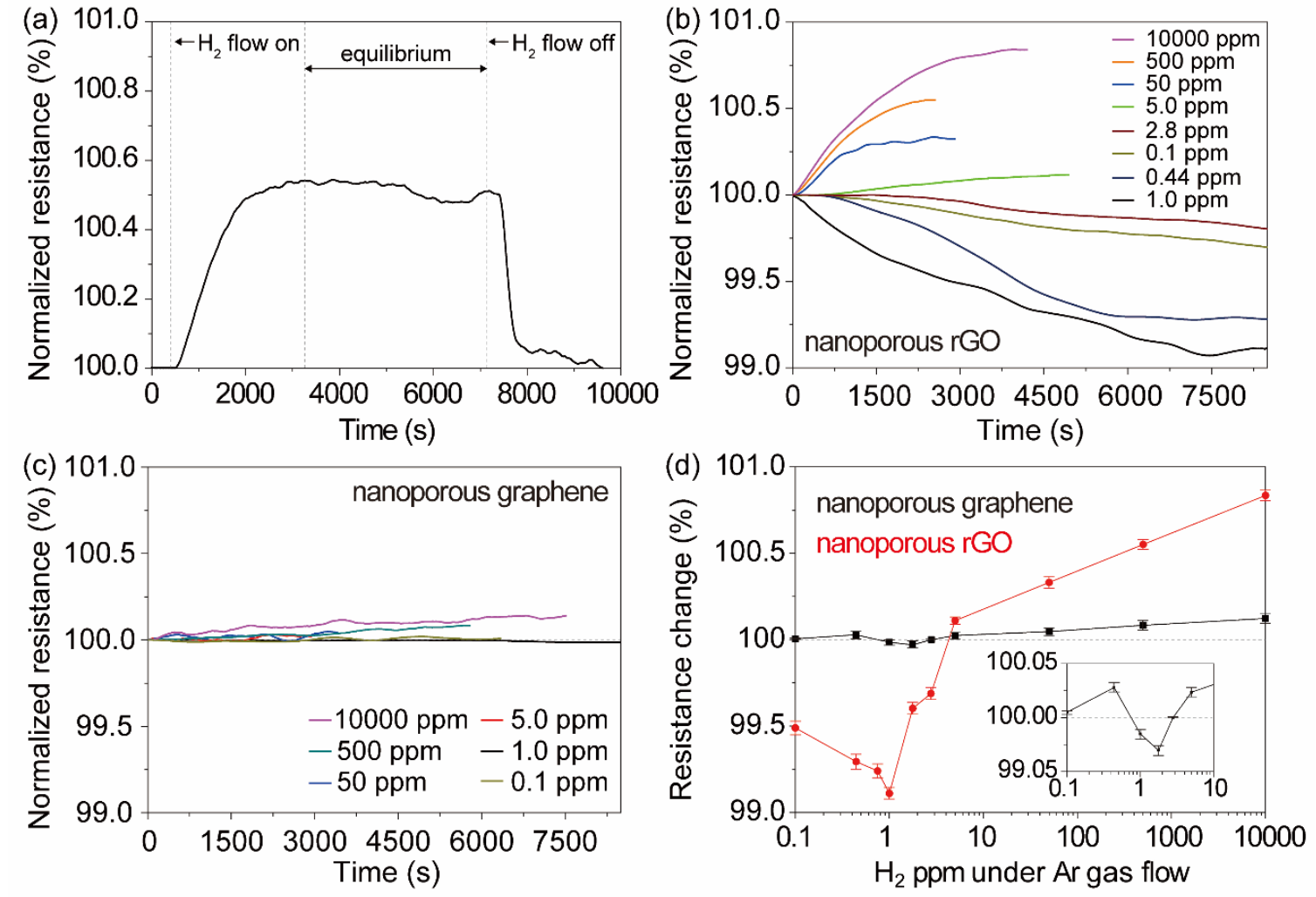

Figure 3. Hydrogen detection ability of nanoporous $\mathrm{rGO}$ under $\mathrm{H}_{2} / \mathrm{Ar}$ gas flow at 1 atmosphere. (a) Reversible feature of nanoporous rGO. Time dependence of resistance change (\%) on (b) nanoporous rGO and (c) pristine nanoporous graphene. (d) $\mathrm{H}_{2}$ volume concentration (ppm) dependence of resistance change (\%) of nanoporous rGO with an oxygen content of 20.0 at. $\%$ and pristine nanoporous graphene. Error bars were estimated by fluctuations during measurements.

\subsection{DFT Calculations}

To elucidate the resistance behaviors, we performed DFT calculations for molecular physisorption of $\mathrm{H}_{2}$ on the surface of graphene and graphene oxide (Figure $4 \mathrm{a}-\mathrm{d}$ and Figure S8 and Table 1). We employed a nanographene cluster model with $\mathrm{C}_{54} \mathrm{H}_{18}$ and partly oxidized the nanographene 
to introduce oxygen-containing functional groups such as hydroxyl, epoxide, ether, ketone, and carboxyl groups for the adsorption of a single $\mathrm{H}_{2}$ molecule (Figure S9). The adsorption energy of $\mathrm{H}_{2}$ was calculated in these models and was $-3.14 \mathrm{kcal} / \mathrm{mol}$ for $\mathrm{C}_{54} \mathrm{H}_{18}$ with two hydroxyl groups, $-2.73 \mathrm{kcal} / \mathrm{mol}$ for $\mathrm{C}_{54} \mathrm{H}_{18}$ with two epoxide groups, $-2.72 \mathrm{kcal} / \mathrm{mol}$ for $\mathrm{C}_{54} \mathrm{H}_{18}$ with a carboxyl group, and $-2.88 \mathrm{kcal} / \mathrm{mol}$ for $\mathrm{C}_{53} \mathrm{H}_{18}$ with an ether and a ketone group; these values were lower than that for $\mathrm{C}_{54} \mathrm{H}_{18}$ without any functional groups (i.e., $-1.58 \mathrm{kcal} / \mathrm{mol}$ ), and there were no significant differences in the functional groups. In the models, it was found that two kinds of charge transfer phenomena occurred: (1) from oxygen-containing functional groups to graphene oxide (i.e., hole doping initially occurred from oxygen-containing functional groups to graphene) and (2) from a single $\mathrm{H}_{2}$ molecule to graphene oxide with +0.020 e (i.e., additional hole doping occurred from $\mathrm{H}_{2}$ to graphene) (Figure 4 and Figure S10 and Table 1). This suggests that the np-rGO before adsorption was electron-deficient because of the oxidized functional groups and became further electron-deficient after $\mathrm{H}_{2}$ adsorption. Moreover, the energy levels of the highest occupied molecular orbital (HOMO) and lowest unoccupied molecular orbital (LUMO) decreased after the adsorption (Table 1). In particular, the energy level of the LUMO of the $\mathrm{C}_{54} \mathrm{H}_{18}$ with two hydroxyl groups showed the highest reduction, in which the adsorption of $\mathrm{H}_{2}$ modified the electronic state of the $\mathrm{rGO}$, benefitting the sequential adsorption of additional $\mathrm{H}_{2}$. Notably, we found a sequential adsorption of three additional $\mathrm{H}_{2}$ molecules by the $\mathrm{C}_{54} \mathrm{H}_{18}$ model with two hydroxyl groups $\left(-10.90 \mathrm{kcal} / \mathrm{mol}\right.$ in total) and a charge transfer $\left(+0.074\right.$ e by four $\mathrm{H}_{2}$ molecules) from the additional $\mathrm{H}_{2}$ molecule on graphene oxide further occurred (Figure S11 and Table S2).
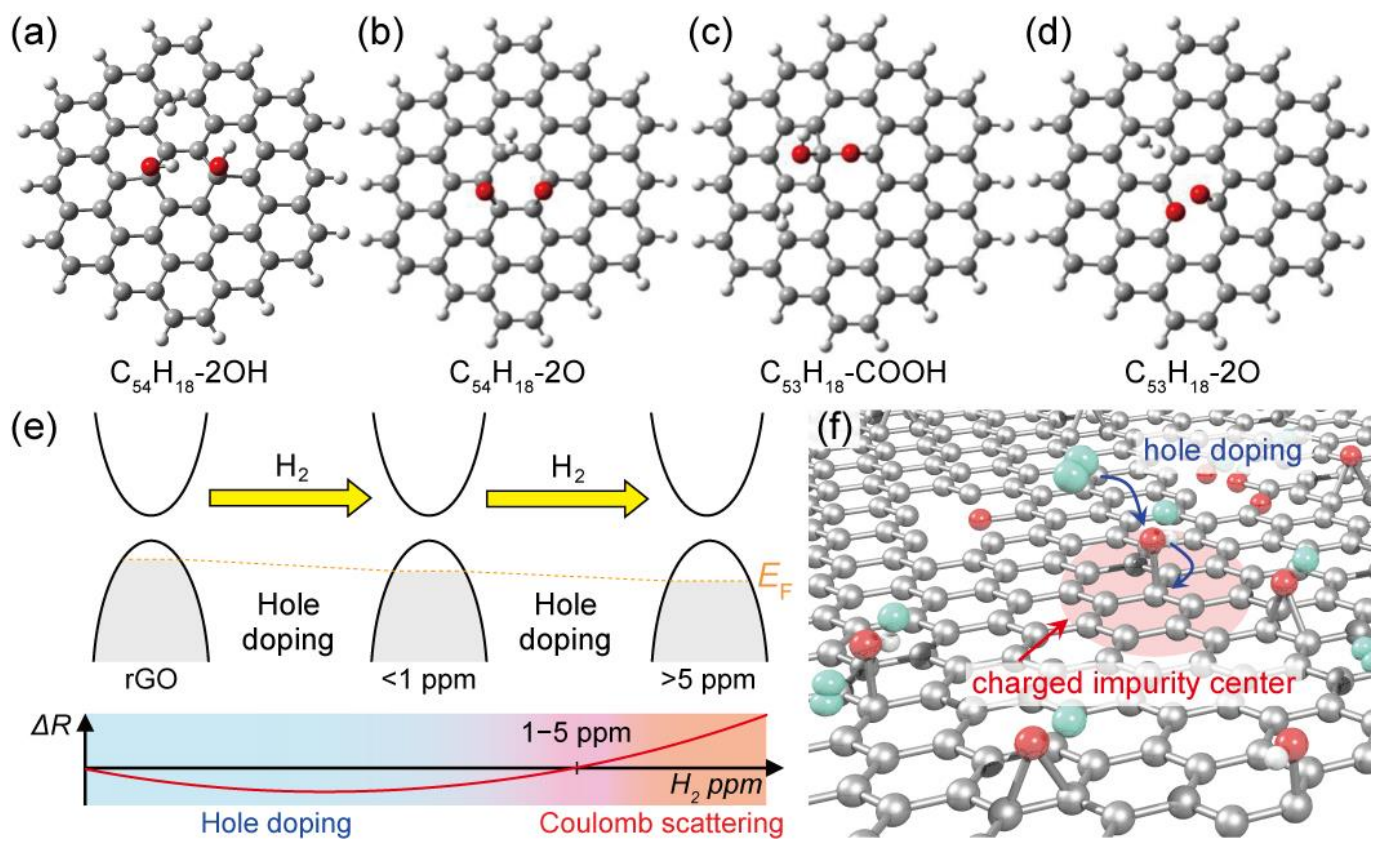

Figure 4. Density functional theory (DFT)-calculated adsorption of molecular hydrogen on graphene oxide and mechanism of resistance change. Graphene oxide with (a) two hydroxyl groups, (b) two epoxide groups, (c) a carboxyl group, and (d) ether and ketone groups after adsorption of molecular hydrogen. (e) Charge transfer effect and electronic density of states on the nanoporous rGO before and after $\mathrm{H}_{2}$ adsorption with expected resistance changes. (f) Coulomb scattering effect on nanoporous rGO after adsorption. The oxygen-containing functional groups act as charged impurity centers enhanced by hole doping from the adsorbed $\mathrm{H}_{2}$. 
Table 1. Summary of the highest occupied molecular orbital (HOMO) energy level, the lowest unoccupied molecular orbital (LUMO) energy level, the shift of HOMO $\left(\Delta E_{\mathrm{HOMO}}\right)$ and LUMO $\left(\Delta E_{\mathrm{LUMO}}\right)$ energy level and cluster total energy before and after adsorption of molecular hydrogen. Charge transfer from $\mathrm{H}_{2}$ to GO indicates the sum of the Mulliken charge of the GO model.

\begin{tabular}{|c|c|c|c|c|c|c|}
\hline & \multicolumn{2}{|c|}{ Before Absorption of $\mathrm{H}_{2}$} & \multicolumn{2}{|c|}{ After Absorption of $\mathbf{H}_{2}$} & \multirow[b]{2}{*}{$\begin{array}{l}\Delta E_{\mathrm{abs}} \\
(\mathrm{kcal} / \mathrm{mol})\end{array}$} & \multirow[b]{2}{*}{$\begin{array}{l}\text { Charge Transfer } \\
\text { from } \mathrm{H}_{2} \text { to GO }\end{array}$} \\
\hline & $\begin{array}{l}\text { HOMO } \\
(\mathrm{eV})\end{array}$ & $\begin{array}{l}\text { LUMO } \\
(\mathrm{eV})\end{array}$ & $\begin{array}{l}\Delta E_{\text {номо }} \\
(\mathrm{eV})\end{array}$ & $\begin{array}{l}\Delta E_{\text {LUMO }} \\
(\mathrm{eV})\end{array}$ & & \\
\hline $\mathrm{C}_{54} \mathrm{H}_{18}$ & -0.19069 & -0.08710 & -0.0002 & -0.0001 & -1.58 & -0.007 e \\
\hline $\mathrm{C}_{54} \mathrm{H}_{18}-2 \mathrm{OH}$ & -0.19323 & -0.09767 & -0.0004 & -0.0007 & -3.14 & $+0.023 \mathrm{e}$ \\
\hline $\mathrm{C}_{54} \mathrm{H}_{18}-2 \mathrm{O}$ & -0.19819 & -0.09185 & -0.0004 & -0.0005 & -2.73 & $+0.020 \mathrm{e}$ \\
\hline $\mathrm{C}_{53} \mathrm{H}_{18}-\mathrm{COOH}$ & -0.17395 & -0.12959 & -0.0003 & -0.0005 & -2.72 & $+0.018 \mathrm{e}$ \\
\hline $\mathrm{C}_{53} \mathrm{H}_{18}-2 \mathrm{O}$ & -0.18408 & -0.09939 & -0.0003 & -0.0007 & -2.88 & $+0.019 \mathrm{e}$ \\
\hline
\end{tabular}

\section{Discussion}

The concentrations of adsorbed $\mathrm{H}_{2}$ lower than $1 \mathrm{ppm}$ showed negative resistance changes, while those higher than $5 \mathrm{ppm}$ showed positive resistance changes. The high resistance changes are attributed to the high oxidation level of the samples (Figure S7) and lower than 1 ppm or higher than $500 \mathrm{ppm} \mathrm{H}_{2}$ concentrations (Figure 3 and Figure S7). This suggests that low amounts of adsorbed $\mathrm{H}_{2}$ should promote the charge transfer effect (Table 1), while high amounts of adsorbed $\mathrm{H}_{2}$ should present a larger influence on resistance change and promote an additional charge transfer effect on the oxidized functional groups (Table S2). Combining the experimental results and DFT calculations, two mechanisms of resistance change could arise for the threshold amount of 1-5 ppm $\mathrm{H}_{2}$ under $\mathrm{H}_{2} / \mathrm{Ar}$ gas flow (30 sccm in total). Below 1 ppm $\mathrm{H}_{2}$, contribution of Coulomb scattering by the adsorbed $\mathrm{H}_{2}$ was not dominant/apparent and the charge transfer from $\mathrm{H}_{2}$ to np-rGO was a major effect. In this case, further hole doping from the adsorbed $\mathrm{H}_{2}$ of the p-type np-rGO reduced the resistance (Figure 4e). Conversely, above $5 \mathrm{ppm} \mathrm{H}_{2}$, Coulomb scattering was the dominant effect, and charge transfer from $\mathrm{H}_{2}$ to np-rGO was a minor effect. The resistance was simply enhanced by the increase of charged

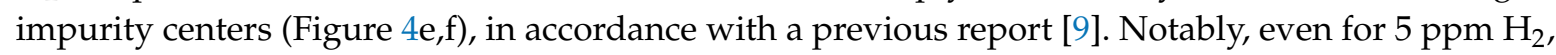
it was observed that the resistance firstly decreased from $0 \mathrm{~s}$ to $300 \mathrm{~s}$ (charge transfer domination) and gradually increased after $300 \mathrm{~s}$ (Coulomb scattering domination) with an increase in hydrogen concentration (Figure S12). Thus, in the range from 1 to $5 \mathrm{ppm} \mathrm{H}_{2}$, the Coulomb scattering and charge transfer effects may be comparable, giving rise to a local minimum. Moreover, the DFT calculations suggest that the hydroxyl groups play an important role in the sequential adsorption of a large amount of $\mathrm{H}_{2}$. The np-rGO with an oxygen content of 20.0 at.\% (hydroxyl/epoxide group: 10.7 at.\%) showed the largest change of resistance values at higher $\mathrm{H}_{2} \mathrm{ppm}$ values in comparison to the nanoporous graphene and np-rGO with oxygen contents of 10.8 at.\% (hydroxyl/epoxide group: 2.5 at.\%) and 18.2 at.\% (hydroxyl/epoxide group: 6.3 at.\%). Furthermore, open porous structures with large total surface areas whose surface was modified by the oxygen-containing functional groups significantly promoted mass transfer and increased the sensitivity of molecular physisorption of non-polar $\mathrm{H}_{2}$. The excellent transport properties resulting from such monolithic characteristics supported accurate detection of resistance changes.

\section{Conclusions}

We developed a novel 3D nanoporous rGO for molecular hydrogen detection at room temperature under gas flow conditions. The detection mechanisms of molecular hydrogen were revealed by using 3D nanoporous rGO specimens featuring a large surface area, a single bicontinuous monolithic sheet morphology, and unique transport properties (non-electron hopping conduction), and were found to be based on the charge transfer effect and Coulomb scattering effect. Moreover, DFT calculations revealed that hydroxyl, epoxide, ether, ketone, and carboxyl groups are preferable molecular physisorption sites, and 
that hydroxyl groups benefit from the sequential adsorption of molecular hydrogen. Nanoporous rGO with tunable oxygen-containing functional groups could provide a general platform for a room-temperature physisorption-type gas sensor and provide a new design direction for nanoporous material-based gas sensors for combustible gases.

Supplementary Materials: The following are available online at http://www.mdpi.com/1996-1944/13/10/2259/s1, Figure S1-S11, Table S2.

Author Contributions: Conceptualization, Y.I.; methodology, Y.I., J.-i.F., and Y.T.; theoretical calculations, M.K. and Y.S.; writing —original draft preparation, Y.I.; writing-review and editing, M.K., Y.S., and Y.T. All authors have read and agreed to the published version of the manuscript.

Funding: This work was sponsored by JSPS Grant-in-Aid for Scientific Research on Innovative Areas “Discrete Geometric Analysis for Materials Design" Grant Numbers JP18H04477 and JP20H04628; JSPS KAKENHI Grant Numbers JP18K14174, JP17K14074, JP19K05195, and JP19K22226; JST-PRESTO “Creation of Innovative Core Technology for Manufacture and Use of Energy Carriers from Renewable Energy" Grant Number JPMJPR1541; the Toyota Mobility Foundation; the NIMS microstructural characterization platform as a program of the "Nanotechnology Platform" of MEXT, Japan; the University of Tsukuba Basic Research Support Program Type S, University of Tsukuba; and the cooperative program (Proposal No. 20G0002) of CRDAM-IMR, Tohoku University.

Acknowledgments: We thank Kazuyo Omura at the Institute for Material Research of Tohoku University for XPS measurements.

Conflicts of Interest: The authors declare no conflict of interest.

\section{References}

1. Mazloomi, K.; Gomes, C.C. Hydrogen as an energy carrier: Prospects and challenges. Renew. Sust. Energy Rev. 2005, 16, 3024-3033. [CrossRef]

2. Muradov, N.Z.; Veziroğlu, T.N. "Green" path from fossil-based to hydrogen economy: An overview of carbon-neutral technologies. Int. J. Hydrog. Energy 2008, 33, 6804-6839. [CrossRef]

3. Moseley, P.T. Solid state gas sensors. Meas. Sci. Technol. 1997, 8, 223-237. [CrossRef]

4. Capone, S.; Forleo, A.; Francioso, L.; Rella, R.; Siciliano, P.; Spadavecchia, J.; Presicce, D.S.; Taurino, A.M. Solid state gas sensors: State of the art and future activities. J. Optoelectron. Adv. Mater. 2003, 5, 1335-1348. [CrossRef]

5. Kong, J.; Franklin, N.R.; Zhou, C.; Chapline, M.G.; Peng, S.; Cho, K.; Dai, H. Nanotube molecular wires as chemical sensors. Science 2000, 287, 622-625. [CrossRef]

6. Collins, P.G.; Bradley, K.; Ishigami, M.; Zettl, A. Extreme oxygen sensitivity of electronic properties of carbon nanotubes. Science 2000, 287, 1801-1804. [CrossRef]

7. Wagner, T.; Haffer, S.; Weinberger, C.; Klaus, D.; Tiemann, D. Mesoporous materials as gas sensors. Chem. Soc. Rev. 2013, 42, 4036-4053. [CrossRef]

8. Schedin, F.; Geim, A.K.; Morozov, S.V.; Hill, E.W.; Blake, P.; Katsnelson, M.I.; Novoselov, K.S. Detection of individual gas molecules adsorbed on graphene. Nat. Mater. 2007, 6, 652-655. [CrossRef]

9. Sun, J.; Muruganathan, M.; Mizuta, H. Room temperature detection of individual molecular physisorption using suspended bilayer graphene. Sci. Adv. 2016, 2, e1501518. [CrossRef]

10. Yavari, F.; Koratkar, N. Graphene-based chemical sensors. J. Phys. Chem. Lett. 2012, 3, 1746-1753. [CrossRef]

11. Yoon, H.J.; Jun, D.H.; Yang, J.H.; Zhou, Z.; Yang, S.S.; Cheng, M.-C. Carbon dioxide gas sensor using a graphene sheet. Sens. Actuators B Chem. 2011, 157, 310-313. [CrossRef]

12. Yavari, F.; Chen, Z.; Thomas, A.V.; Ren, W.; Cheng, H.-M.; Koratkar, N. High sensitivity gas detection using a macroscopic three-dimensional graphene foam network. Sci. Rep. 2011, 1, 166. [CrossRef] [PubMed]

13. Chen, G.; Paronyan, T.M.; Harutyunyan, A.R. Sub-ppt gas detection with pristine graphene. Appl. Phys. Lett. 2012, 101, 053119. [CrossRef]

14. Robinson, J.T.; Perkins, F.K.; Snow, E.S.; Wei, Z.; Sheehan, P.E. Reduced Graphene Oxide Molecular Sensors. Nano Lett. 2008, 8, 3137-3140. [CrossRef] [PubMed]

15. Lipatov, A.; Varezhnikov, A.; Wilson, P.; Sysoev, V.; Kolmakov, A.; Sinitskii, A. Highly selective gas sensor arrays based on thermally reduced graphene oxide. Nanoscale 2013, 5, 5426-5434. [CrossRef]

16. Paul, P.; Badhulika, S.; Saucedo, N.M.; Mulchandani, A. Graphene Nanomesh As Highly Sensitive Chemiresistor Gas Sensor. Anal. Chem. 2012, 84, 8171-8178. [CrossRef] [PubMed] 
17. Fowler, J.D.; Allen, M.J.; Tung, V.C.; Yang, U.; Kaner, R.B.; Weiller, B.H. Practical Chemical Sensors from Chemically Derived Graphene. ACS Nano 2009, 3, 301-306. [CrossRef]

18. Yavari, F.; Castillo, E.; Gullapalli, H.; Ajayan, P.M.; Koratkar, N. High sensitivity detection of $\mathrm{NO}_{2}$ and $\mathrm{NH} 3$ in air using chemical vapor deposition grown graphene. Appl. Phys. Lett. 2012, 100, 203120. [CrossRef]

19. Kitayama, H.; Ekayev, M.C.; Ohba, T. Piezoresistive and chemiresistive gas sensing by metal-free graphene layers. Phys. Chem. Chem. Phys. 2020, 22, 3089-3096. [CrossRef]

20. Chua, B.H.; Lo, C.F.; Nicolosi, J.; Chang, C.Y.; Chen, V.; Strupinski, W.; Pearton, S.J.; Ren, F. Hydrogen detection using platinum coated graphene grown on SiC. Sens. Actuators B 2011, 157, 500-503. [CrossRef]

21. Shafiei, M.; Spizzirri, P.G.; Arsat, R.; Yu, J.; Plessis, J.; Dubin, S.; Kaner, R.B.; Kalantar-zadeh, K.; Wlodarski, W. Platinum/Graphene Nanosheet/SiC Contacts and Their Application for Hydrogen Gas Sensing. J. Phys. Chem. C 2010, 114, 13796-13801. [CrossRef]

22. Wu, W.; Liu, Z.; Jauregui, L.A.; Yu, Q.; Pillai, R.; Cao, H.; Bao, J.; Chen, P.; Pei, S.-S. Wafer-scale synthesis of graphene by chemical vapor deposition and its application in hydrogen sensing. Sens. Actuators B 2010, 150, 296-300. [CrossRef]

23. Pak, Y.; Kim, S.-M.; Jeong, H.; Kang, C.G.; Park, J.S.; Song, H.; Lee, R.; Myoung, N.; Lee, B.H.; Seo, S.; et al. Palladium-Decorated Hydrogen-Gas Sensors Using Periodically Aligned Graphene Nanoribbons. ACS Appl. Mater. Interfaces 2014, 6, 13293-13298. [CrossRef] [PubMed]

24. Chung, M.G.; Kim, D.-H.; Seo, D.K.; Kim, T.; Im, H.U.; Lee, U.M.; Yoo, J.-B.; Hong, S.-H.; Kang, T.H.; Kim, Y.H. Flexible hydrogen sensors using graphene with palladium nanoparticle decoration. Sens. Actuators B 2012, 169, 387-392. [CrossRef]

25. Johnson, J.L.; Behnam, A.; Pearton, S.J.; Ural, A. Hydrogen Sensing Using Pd-Functionalized Multi-Layer Graphene Nanoribbon Networks. Adv. Mater. 2010, 22, 4877-4880. [CrossRef] [PubMed]

26. Gautam, M.; Jayatiss, A.H. Ammonia gas sensing behavior of graphene surface decorated with gold nanoparticles. Solid-State Electron. 2012, 78, 159-165. [CrossRef]

27. Anand, K.; Singh, O.; Singh, M.P.; Kaur, J.; Singh, R.C. Hydrogen sensor based on graphene/ZnO nanocomposite. Sens. Actuators B 2014, 195, 409-415. [CrossRef]

28. Cuong, T.V.; Pham, V.H.; Chung, J.S.; Shin, E.W.; Yoo, D.H.; Hahn, S.H.; Huh, J.S.; Rue, G.H.; Kim, E.J.; Hur, S.H.; et al. Solution-processed ZnO-chemically converted graphene gas sensor. Mater. Lett. 2010, 64, 2479-2482. [CrossRef]

29. Zhang, Z.; Zou, R.; Song, G.; Yu, L. Highly aligned $\mathrm{SnO}_{2}$ nanorods on graphene sheets for gas sensors. J. Mater. Chem. 2011, 21, 17360-17365. [CrossRef]

30. Russo, P.A.; Donato, N.; Leonardi, S.G.; Baek, S.; Conte, D.E.; Neri, G.; Pinna, N. Room-Temperature Hydrogen Sensing with Heteronanostructures Based on Reduced Graphene Oxide and Tin Oxide. Angew. Chem. Int. Ed. 2012, 51, 11053-11057. [CrossRef]

31. Qiu, H.-J.; Kang, J.L.; Liu, P.; Hirata, A.; Fujita, T.; Chen, M.W. Fabrication of large-scale nanoporous nickel with a tunable pore size for energy storage. J. Power Sources 2014, 247, 896-905. [CrossRef]

32. Ito, Y.; Tanabe, Y.; Qiu, H.-J.; Sugawara, K.; Heguri, S.; Tu, N.H.; Huynh, K.K.; Fujita, T.; Takahashi, T.; Tanigaki, K.; et al. High Quality Three-Dimensional Nanoporous Graphene. Angew. Chem. Int. Ed. 2014, 53, 4822-4826. [CrossRef] [PubMed]

33. Ji, K.; Han, J.; Hirata, A.; Fujita, T.; Shen, Y.; Ning, S.; Liu, P.; Kashani, H.; Tian, Y.; Ito, Y.; et al. Lithium intercalation into bilayer graphene. Nat. Commun. 2019, 10, 275. [CrossRef]

34. Kashani, H.; Ito, Y.; Han, J.; Liu, P.; Chen, M.W. Extraordinary tensile strength and ductility of scalable nanoporous graphene. Sci. Adv. 2019, 5, eaat6951. [CrossRef]

35. Tanabe, Y.; Ito, Y.; Sugawara, K.; Hojo, D.; Koshino, M.; Fujita, T.; Aida, T.; Xu, X.; Huynh, K.K.; Shimotani, H.; et al. Electric Properties of Dirac Fermions Captured into 3D Nanoporous Graphene Networks. Adv. Mater. 2016, 28, 10304-10310. [CrossRef]

36. Ito, Y.; Zhang, W.; Li, J.; Chang, H.; Liu, P.; Fujita, T.; Chen, M.W. 3D Bicontinuous Nanoporous Reduced Graphene Oxide for Highly Sensitive Photodetectors. Adv. Funct. Mater. 2016, 26, 1271-1277. [CrossRef]

37. Becke, A.D. Density-functional thermochemistry. III. The role of exact exchange. J. Chem. Phys. 1993, 98, 5648-5652. [CrossRef]

38. Lee, C.; Yang, W.; Parr, R.G. Development of the Colle-Salvetti correlation-energy formula into a functional of the electron density. Phys. Rev. B 1988, 37, 785-789. [CrossRef] 
39. Grimme, S.; Antony, J.; Ehrlich, S.; Krieg, H.A. A consistent and accurate ab initio parametrization of density functional dispersion correction (DFT-D) for the 94 elements H.-Pu. J. Chem. Phys. 2010, 132, 154104. [CrossRef]

40. Krishnan, R.; Binkley, J.S.; Seeger, R.; Pople, A. Self-consistent molecular orbital methods. XX. A basis set for correlated wave functions. J. Chem. Phys. 1980, 72, 650-654. [CrossRef]

41. Frisch, M.J.; Trucks, G.W.; Schlegel, H.B.; Scuseria, G.E.; Robb, M.A.; Cheeseman, J.R.; Scalmani, G.; Barone, V.; Petersson, G.A. Gaussian 16, Revision A. 03; Gaussian, Inc.: Wallingford, CT, USA, 2016.

42. Ito, Y.; Weitao, C.; Fujita, T.; Tang, Z.; Chen, M.W. High Catalytic Activity of Nitrogen and Sulfur Co-Doped Nanoporous Graphene in the Hydrogen Evolution Reaction. Angew. Chem. Int. Ed. 2015, 54, 2131-2136. [CrossRef]

43. Bernardo, I.D.; Avvisati, G.; Chen, C.; Avila, J.; Asensio, M.C.; Hu, K.; Ito, Y.; Hines, P.; Lipton-Duffin, J.; Rintoul, L.; et al. Topology and doping effects in three-dimensional nanoporous graphene. Carbon 2018, 131, 258-265. [CrossRef]

44. Bernardo, I.D.; Avvisati, G.; Mariani, C.; Motta, N.; Chen, C.; Avila, J.; Asensio, M.C.; Lupi, S.; Ito, Y.; Chen, M.W.; et al. Two-Dimensional Hallmark of Highly Interconnected Three-Dimensional Nanoporous Graphene. ACS Omega 2017, 2, 3691-3697. [CrossRef]

45. Chang, H.; Sun, Z.; Saito, M.; Yuan, Q.; Zhang, H.; Li, J.; Wang, Z.; Fujita, T.; Ding, F.; Zheng, Z.; et al. Regulating Infrared Photoresponses in Reduced Graphene Oxide Phototransistors by Defect and Atomic Structure Control. ACS Nano 2013, 7, 6310-6320. [CrossRef]

46. Mattevi, C.; Eda, G.; Agnoli, S.; Miller, S.; Mkhoyan, A.K.; Celik, O.; Mastrogiovanni, D.; Granozzi, G.; Garfunkel, E.; Chhowalla, M. Evolution of Electrical, Chemical, and Structural Properties of Transparent and Conducting Chemically Derived Graphene Thin Films. Adv. Funct. Mater. 2009, 19, 2577-2583. [CrossRef]

47. Wang, L.; Wang, H.Y.; Wang, Y.; Zhu, S.J.; Zhang, Y.L.; Zhang, J.H.; Chen, Q.-D.; Han, W.; Xu, H.-L.; Yang, B.; et al. Direct Observation of Quantum-Confined Graphene-Like States and Novel Hybrid States in Graphene Oxide by Transient Spectroscopy. Adv. Mater. 2013, 25, 6539-6545. [CrossRef]

48. Tuinstra, F.; Koenig, J.L. Raman Spectrum of Graphite. J. Chem. Phys. 1970, 53, 1126-1130. [CrossRef]

49. Cancado, L.G.; Jorio, A.; Ferreira, E.H.M.; Stavale, F.; Chete, A.; Capaz, R.B.; Moutinho, M.V.O.; Lombardo, A.; Kulmala, T.S.; Ferrari, A.C. Quantifying Defects in Graphene via Raman Spectroscopy at Different Excitation Energies. Nano Lett. 2011, 11, 3190-3196. [CrossRef]

50. Lucchese, M.M.; Stavale, F.; Ferreira, E.H.M.; Vilani, C.; Moutinho, M.V.O.; Capaz, R.B.; Achete, C.A.; Jorio, A. Quantifying ion-induced defects and Raman relaxation length in graphene. Carbon 2010, 48, 1592-1597. [CrossRef]

51. Ito, Y.; Tanabe, Y.; Sugawara, K.; Koshino, M.; Takahashi, T.; Tanigaki, K.; Aoki, H.; Chen, W.M. Three-dimensional porous graphene networks expand graphene-based electronic device applications. Phys. Chem. Chem. Phys. 2018, 20, 6024-6033. [CrossRef]

52. Chang, H.; Sun, Z.; Yuan, Q.; Ding, F.; Tao, X.; Yan, F.; Zheng, Z. Thin film field-effect phototransistors from bandgap-tunable, solution-processed, few-layer reduced graphene oxide films. Adv. Mater. 2010, 22, 4872-4876. [CrossRef]

(C) 2020 by the authors. Licensee MDPI, Basel, Switzerland. This article is an open access article distributed under the terms and conditions of the Creative Commons Attribution (CC BY) license (http://creativecommons.org/licenses/by/4.0/). 